\title{
A relação entre Dialetologia e História: Reflexões teórico-metodológicas para o estudo do português usado em Minas Gerais
}

Ana Paula Antunes Rocha ${ }^{a}$ Francisco Eduardo Andrade ${ }^{b}$

\begin{abstract}
Resumo
Este texto apresenta uma sintese dos trabalhos dialetológicos já realizados sobre Minas Gerais. A descrição do português usado no estado aponta a delimitação de três ou quatro áreas dialetais básicas, divisão que aparentemente pode ser explicada por fatores históricos. O objetivo do texto é discutir os problemas decorrentes da tentativa de se explicar a divisão dialetal do estado à luz da cartografia e da historicidade convencionais, as quais nem sempre levam em conta o dinamismo do tempo e do espaço.

PALAVRAS-CHAVE: Dialetologia; História; dialetos mineiros; representação espacial.
\end{abstract}

\footnotetext{
a Leciona Língua Portuguesa e Linguística no curso de Letras da UFOP, ap.rocha@ymail.com.

b Professor da Universidade Federal de Ouro Preto, coordenador da coleção Historiografia de Minas Gerais da Autêntica Editora, franciscoeandrade@hotmail.com.
} 


\section{Introdução}

Um instrumento imprescindível aos estudos dialetológicos é a confecção de cartas, que são mapas cartográficos sobre os quais se apresentam os dados obtidos nas pesquisas de campo. Também a interdisciplinaridade é uma das características básicas desses estudos, como se vê nas palavras de Cardoso (2010, p. 15), que define a dialetologia ${ }^{1}$ como "um ramo dos estudos linguísticos que tem por tarefa identificar, descrever e situar os diferentes usos em que uma língua se diversifica, conforme a sua distribuição espacial, sociocultural e cronológica".

Ainda segundo a autora,

o espaço geográfico evidencia a particularidade de cada terra, exibindo a variedade que a língua assume de uma região para outra, como forma de responder à diversidade cultural, à natureza da formação demográfica da área, à própria base linguística preexistente e à interferência de outras línguas que se tenham feito presentes naquele espaço no curso de sua história. (CARDOSO, 2010, p. 15).

O objetivo deste texto é propor uma reflexão a respeito das formas possíveis de, por meio da cartografia, expor a relação existente entre uma dada configuração dialetológica e o contexto extralinguístico no qual ela se encontra e a partir do qual ela se organiza, entendido esse contexto não apenas como um conjunto de fatores referentes aos informantes, tais como faixa etária, sexo, escolaridade, mas como um contexto tão dinâmico quanto a história e as diversas relações sociais que se dão entre os falantes.

Embora se objetive fazer uma reflexão de caráter geral, que valha aos estudos dialetológicos de forma ampla, o foco, neste texto, será o estado de Minas Gerais, ou seja, tem-se por meta refletir sobre como se pode interpretar a realidade dialetológica de Minas - que já foi mapeada por Nascentes (1953), por Ribeiro et al (1977), por Zágari (1998) e atualmente está sendo mapeada pela equipe do Projeto ALiB (Projeto Atlas Linguístico do Brasil) - à luz de estudos de outras áreas diferentes da Linguística que tratem desse mesmo recorte espacial.

Para tanto, nas seções seguintes deste artigo, se discorrerá

${ }^{1}$ Neste texto, Geografia Linguística, Dialetologia e Geolinguística estão sendo usados como sinônimos, embora não se desconheça que os termos guardam, entre si, certas diferenças. sobre os estudos dialetológicos de Minas Gerais mencionados no parágrafo anterior e sobre estudos que já buscaram interpretar o espaço mineiro à luz de alguma das muitas possibilidades interdisiplinares apontadas por Cardoso nas citações anteriores. 


\section{Descrição espacial da realidade linguística de Minas Gerais}

O EALMG ("Esboço de um Atlas Linguístico de Minas Gerais") faz parte de um conjunto de atlas regionais surgidos no país desde a década de 1960 para atender ao Decreto $\mathrm{n}^{\mathrm{o}} 30.643 / 52^{2}$, que previa, entre outros pontos, a elaboração de um atlas linguístico do Brasil, o qual somente na década de 1990 começou a ser elaborado.

Os atlas regionais do território brasileiro cujos autores ou colaboradores elaboram atualmente o "Atlas Linguístico do Brasil" (doravante ALiB) são estaduais, apesar de se saber que os limites dialetológicos não coincidem necessariamente com os limites geopolíticos. Devido à impossibilidade de se realizar um atlas nacional no momento de publicação do Decreto mencionado - em função da extensão do país e da falta de uma equipe técnica já suficientemente preparada -, foram realizados atlas regionais, mais precisamente estaduais. Trata-se de um procedimento operacional necessário e viável. São cinco os atlas estaduais feitos com o propósito de descrição regional e de preparação do atlas nacional: (i) "Atlas Prévio dos

${ }^{2} \mathrm{O}$ Decreto $\mathrm{n}^{\circ} 30.643$, de 20/03/1952 definia a finalidade da $\mathrm{Co}-$ missão de Filologia da Casa de Rui Barbosa, recentemente criada: "A Comissão de Filologia promoverá pesquisas em todo o vasto campo de filologia portuguesa [...], sendo sua finalidade principal a elaboração do Atlas Linguístico do Brasil." Tanto quanto outras iniciativas de caráter nacionalista do segundo governo do presidente Getúlio Vargas, o atlas nacional teria a finalidade de registrar a unidade na diversidade.

"Embora "dialeto" e "falar" não sejam sinônimos na bibliografia que trata do assunto, não se entrará neste texto no detalhamento das diferenças que os caracterizam. Note-se, porém, a preferência de Nascentes e de Zágari pelo termo "falar".
Falares Baianos" (Rossi, 1964), conhecido como APFB; (ii) "Atlas Linguístico de Sergipe", conhecido como ALS e publicado por Ferreira et al. (1987) com originais que já estavam prontos desde 1973; (iii)“Esboço de um Atlas Linguístico de Minas Gerais" (Ribeiro et al., 1977), conhecido como EALMG ou ALEMIG; (iv) "Atlas Linguístico da Paraíba" (Aragão; Menezes, 1984), conhecido como ALP; (v) "Atlas Linguístico do Paraná" (Aguilera, 1994), conhecido como ALPR.

A fim de ter uma ideia inicial da distribuição espacial dos dialetos ou falares brasileiros, para assim nortear o trabalho empírico que mais tarde seria feito por meio da coleta de dados em pesquisas de campo, Nascentes (1953) formaliza as pistas para se realizar essa descrição e propõe a existência de algumas grandes áreas dialetais no Brasil, conforme se vê na figura 1.

A publicação do EALMG, em 1977, confirma parcialmente a proposta de Nascentes. O atlas mineiro apresenta cartas que levam a uma tripartição da fala mineira, a qual, mais tarde, foi formalizada por Zágari (1998), que propõe a seguinte divisão dialetal para o estado: falar ${ }^{3}$ baiano - caracterizado pelo abaixamento de vogais pretônicas -, falar paulista - caracterizado pela presença do " $r$ " 
retroflexo - e falar mineiro - caracterizado pela ausência dos traços anteriores -, conforme mapa seguinte, na figura 2.

Figura 1 - Grandes áreas dialetais no Brasil, segundo Nascentes

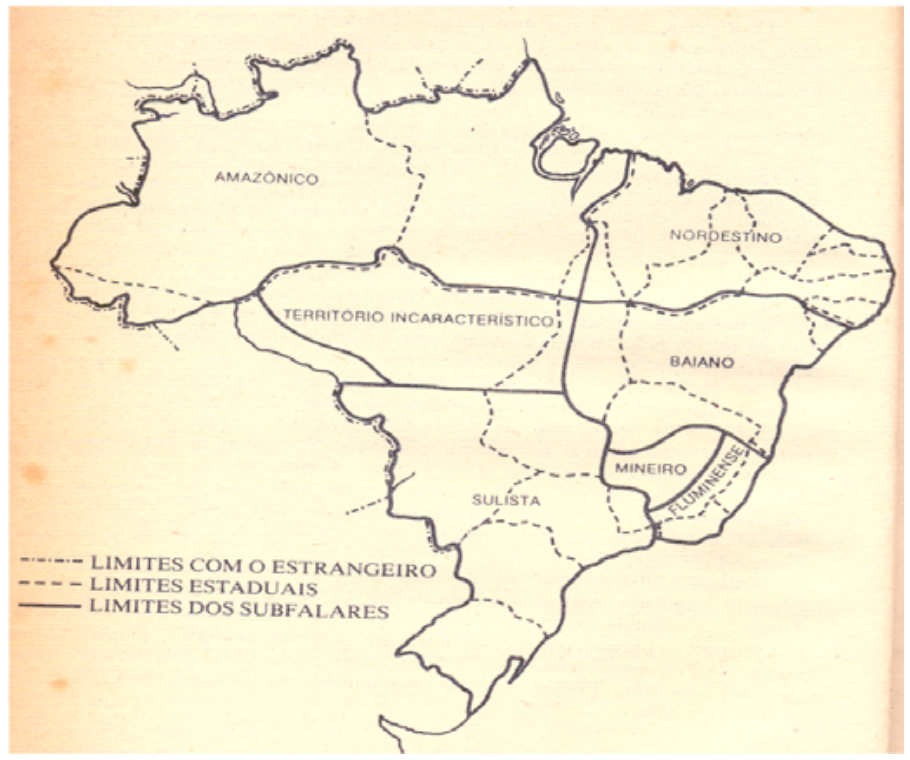

Fonte: Nascentes (1953).

Figura 2 - Divisão dialeteal para MG, segundo Zágari

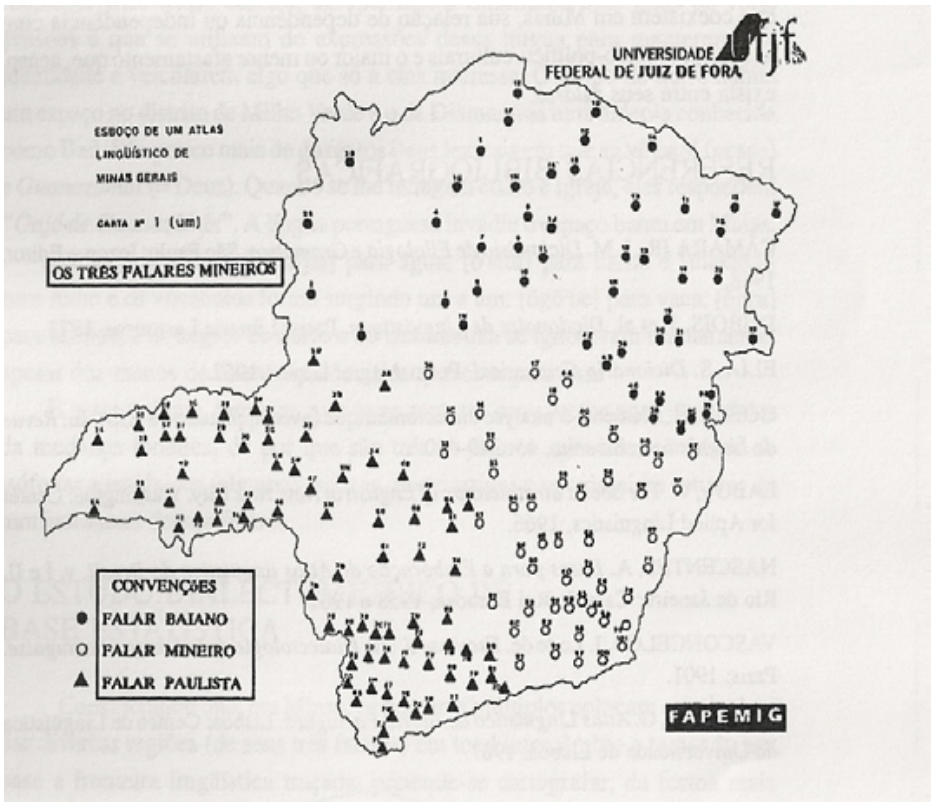

Fonte: Zágari (1998). 
Como se afirmou, Zágari chegou a essa proposta por meio das isófonas presentes no EALMG; as isoléxicas confirmam essa tripartição apenas parcialmente, conforme destacam Rocha e Ramos (2010).A proposta de Zágari diferencia-se da de Nascentes (1953), segundo a qual haveria, em Minas Gerais, quatro, e não três falares, incluindo-se, entre eles, o fluminense (cf. figura 1).

Em linhas gerais, os atlas linguísticos regionais já publicados no Brasil adotaram a seguinte metodologia: escolheram-se os pontos (as localidades) a serem investigados; neles, selecionaram-se alguns informantes que foram submetidos a um inquérito contemplando questões fonéticas ou lexicais ou morfossintáticas (ou dos três tipos ao mesmo tempo); as respostas foram postas em cartas, que são mapas do estado estudado, nas quais se encontram ou a transcrição das formas recolhidas (cf., por exemplo, a figura 3) ou, no caso das cartas sintéticas, as formas semelhantes documentadas organizadas em zonas demarcadas, que constituem, na carta, isoglossas, que podem ser isoléxicas, como a que se vê na figura 4, ou isófonas, como as que se encontram nas figuras 5 e $6^{4}$. A detecção de áreas dialetais depende da identificação de isoglossas, linhas demarcatórias dos fenômenos característicos de cada área.

Figura 3 - Esboço de um atlas linguístico de MG, carta 1

${ }^{4}$ Nas figuras 4,5 e 6 , as hachuras das cartas mostram a extensão territorial em que se encontra um uso linguístico. As linhas descontínuas nas bordas indicam a atenuação do uso.

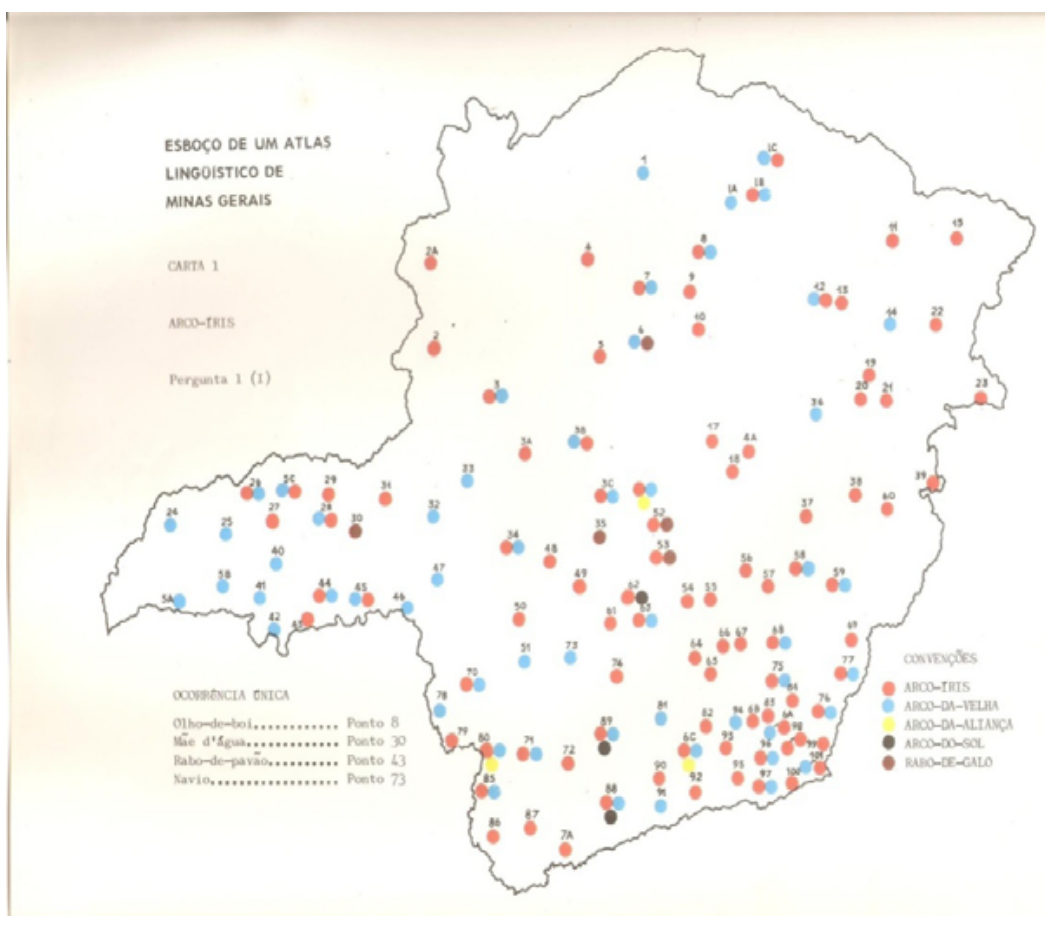

Fonte: Ribeiro et al. (1977). 
Figura 4 - Esboço de um atlas linguístico de MG, carta 55

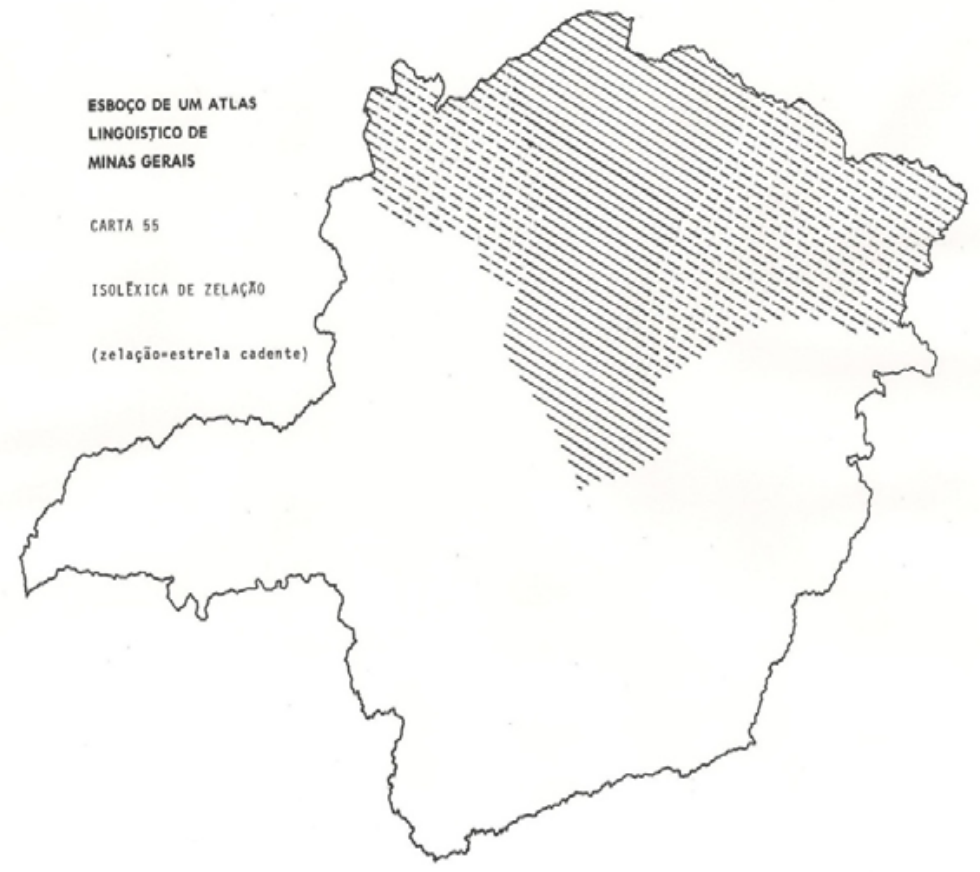

Fonte: Ribeiro et al. (1977).

Figura 5 - Esboço de um atlas linguístico de MG, carta 47

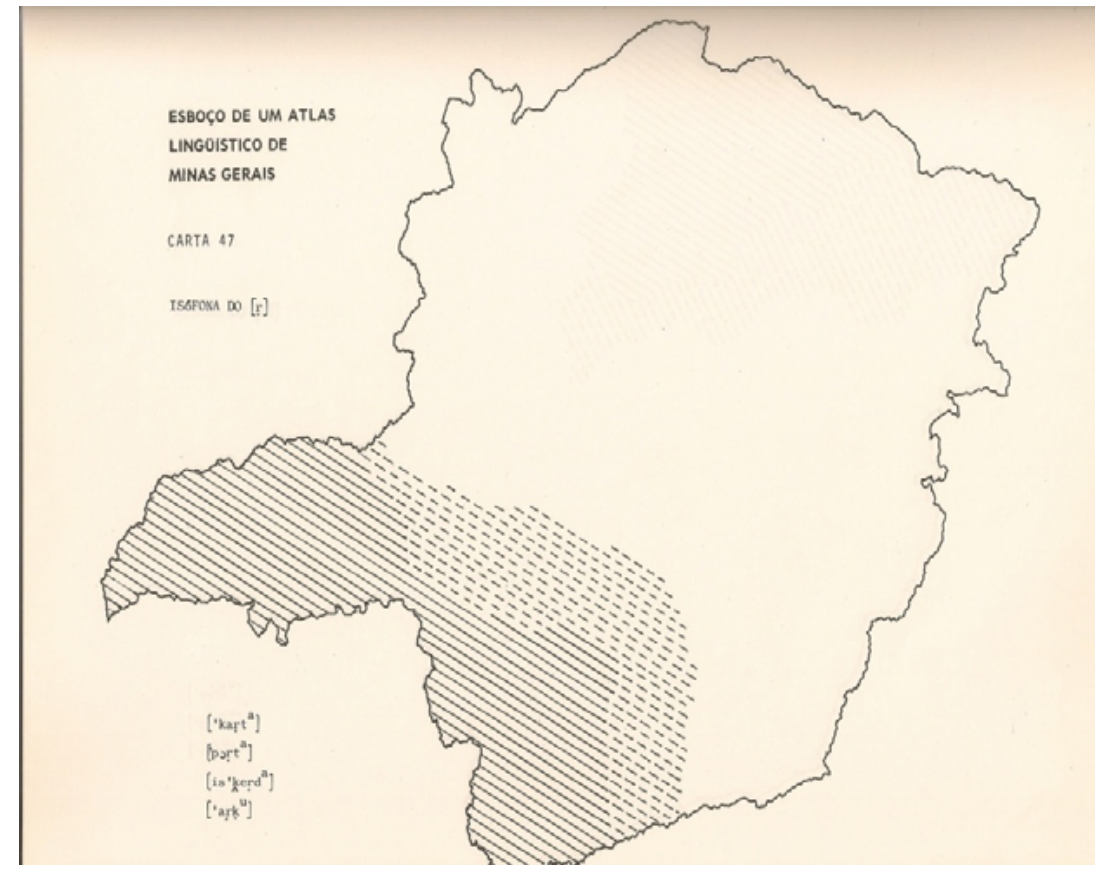

Fonte: Ribeiro et al. (1977). 
Figura 6 - Esboço de um atlas linguístico de MG, carta 46

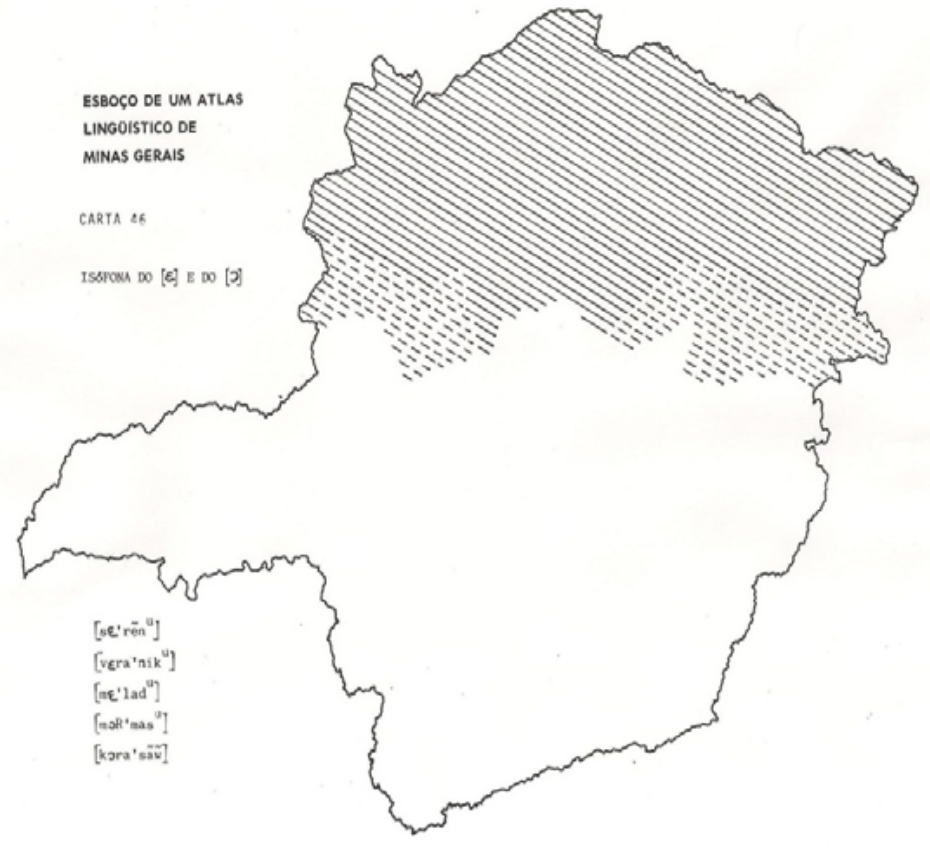

Fonte: Ribeiro et al. (1977).

Tanto a proposta de Zágari - feita a partir de isoglossas encontradas nas cartas do EALMG -, quanto a hipótese de Nascentes - feita de forma mais impressionista, embora muito acertada, conforme se vem comprovando nas últimas décadas - vêm sendo tomadas como ponto de partida para a realização de outros trabalhos que, investigando aspectos diversos da realidade linguística de Minas Gerais, também contribuem para a detecção de áreas dialetais, como é o caso do Projeto Mineirês, coordenado pela professora Jânia Ramos na Universidade Federal de Minas Gerais.

Além das propostas de Nascentes e de Zágari acerca da divisão dialetal encontrada em Minas Gerais, outra obra que muito contribuirá para a depreensão de áreas dialetais no estado será o $\mathrm{ALiB}$, fruto de um projeto interinstitucional que vem sendo executado em todo o território brasileiro desde a década de 1990 com o objetivo de publicar, como o nome já diz, um atlas que descreva a realidade linguística brasileira em diversos aspectos: fonético, morfossintático e lexical.

A publicação dos dados das cidades do interior poderá trazer um novo mapeamento das áreas dialetais brasileiras, 
incluindo as mineiras, que aqui interessa de forma direta. As diferenças que existem entre as propostas de Nascentes e de Zágari, bem como eventuais diferenças que o ALiB venha a apontar, não significam a refutação de um trabalho pelo outro. Cada trabalho baseia-se em coletas feitas numa determinada época, com a aplicação de questionários diferentes. Em Minas Gerais, o Projeto ALiB engloba 23 localidades, enquanto o EALMG englobou 116 nas pesquisas in loco. Todos os atlas estaduais citados anteriormente tiveram uma rede de pontos, em seu estado correspondente, maior do que a do Projeto ALiB. Se a equipe do Projeto ALiB teve enorme dificuldade para realizar a coleta de dados nos pontos selecionados pelo projeto, investigar todas as localidades presentes nos atlas estaduais seria uma tarefa inviável, ou mesmo impossível. A seleção dos pontos é norteada pela observação de determinadas características linguísticas ou por critérios extralinguísticos, como o povoamento, a caracterização cultural, a atividade econômica de uma localidade, a localização do ponto em torno de um acidente geográfico, entre outros critérios possíveis.

Feitas as observações anteriores sobre a realidade linguística de Minas Gerais, pode-se dizer, de forma resumida, que, por ora, têm-se as seguintes informações básicas sobre a distribuição espacial do português em Minas Gerais:

(i) Nascentes (1953) entende haver no estado quatro dos "subfalares brasileiros": o baiano, o mineiro, o sulista e o fluminense, conforme ficou explícito na figura 1.

(ii) Zágari (1998), à luz do EALMG, identifica, por sua vez, apenas três áreas no estado, valendo-se de critérios sobretudo fonéticos e deixando a área do "falar mineiro" propriamente dito como uma área caracterizada pela ausência dos traços marcantes das outras duas áreas, que são o " $r$ " retroflexo no falar paulista e o abaixamento das pretônicas no falar baiano, conforme figuras 2, 5 e 6 .

(iii) Há estudos recentes, como o de Ramos (2012) sobre interjeições, que corroboram a proposta de Nascentes, sem refutar a de Zágari. 
(iv) Há outros que corroboram diretamente a proposta de Zágari, como o de Rocha e Antunes (2014), segundo o qual dados do Projeto ALiB coletados em pontos do interior de Minas mostram que o norte do estado mantém a tendência ao abaixamento das pretônicas, enquanto pontos do Sul do estado e do Triângulo Mineiro mantêm a tendência ao uso do " $r$ " retroflexo.

(v) Há alguns estudiosos, como Barros (2014), investigando a Zona da Mata, principalmente na divisa com o estado do Rio de Janeiro, área conflitante, em princípio, nas propostas de Nascentes e de Zágari; contudo, ainda não há publicações mais conclusivas sobre o assunto.

(vi) Há estudos que apontam, numa determinada localidade, características inesperadas tanto pela proposta de Nascentes quanto pela de Zágari, como o de Antunes e Rangel (2001), que não encontram em Ipatinga o abaixamento das pretônicas esperado pelo fato de a localidade, da região do Vale do Rio Doce, pertencer à área dialetal apontada pelos autores citados como sendo a do falar nordestino.

(vii) Há ainda a publicação de Seabra (2008), que, a partir da toponímia do estado, corrobora parcialmente a proposta de Zágari, sugerindo, porém, uma área típica no Triângulo Mineiro.

(viii) O termo "mineirês", tão usado pelo falante brasileiro para designar os falares de Minas Gerais de forma abrangente, não costuma aparecer na bibliografia técnica e acadêmica que trata do assunto, mas é empregado, por exemplo, no trabalho de Ribeiro (2013) e, neste caso, parece referir-se ao dialeto mineiro do centro do estado, contraposto ao paulista e ao baiano apontados por Zágari.

Sob pena de incorrer em vários erros de ordem epistemológica e metodológica e de tomar como seguras informações históricas duvidosas, o linguista e, mais precisamente, o dialetólogo precisam do apoio de profissionais 
de outras áreas do conhecimento na tentativa de explicar como os falares e os dialetos se distribuem pelo espaço. Por isso, nas próximas seções, serão discutidas a problemática e algumas tentativas de explicar a regionalização do estado de Minas Gerais.

\section{A noção de espaço e suas repercussões nos trabalhos dialetológicos}

Nos estudos dialetológicos, as cartas têm fundamental importância como instrumento metodológico de descrição. Oferecem uma ampla observação horizontal e plana de uma dada região a partir de determinados fatores linguísticos. Analisá-las, porém, exige um nível de detalhamento maior do que a superfície de um mapa pode oferecer e coloca o pesquisador diante de questões que devem ser consideradas sob pena de se reduzir a sua análise a um trabalho superficial e/ou mesmo equivocado.

Conforme já se afirmou, o resultado mais imediato do trabalho dialetológico são as cartas, ferramentas nas quais os resultados obtidos nas pesquisas de campo são expostos e oferecem, entre outras possibilidades, a de se encontrarem isoglossas, com as quais se torna possível a detecção de áreas dialetais. Apesar das mudanças sofridas pela Dialetologia, tanto em termos conceptuais quanto em termos metodológicos (neste último ponto, graças principalmente aos avanços tecnológicos), as cartas continuam sendo seu instrumento de descrição mais importante e conhecido.

Com isso, a palavra "espaço" torna-se inevitável nos estudos dialetológicos. Tanto quanto acontece em outras áreas, é provável que o espaço possa, em geral, ser tomado de forma excessivamente simplificada, como algo já constituído, e não como algo dinâmico, em relação direta com as realizações humanas que a ele se integram. Se se apreende o espaço descrito numa pesquisa dialetológica fazendo-se tábula rasa da complexidade que esse conceito traz em si, corre-se o risco de se ter que arcar com consequências indesejáveis e imprevistas. A mais óbvia e simples repousa sobre o fato de uma pesquisa dialetológica demandar, para sua realização, um tempo compreendido entre o início da pesquisa e seu término, o que gera um intervalo no qual vários eventos podem interferir no 
resultado final da pesquisa, principalmente em virtude de as características de determinadas localidades se alterarem entre o início e o término do trabalho.

Como também já se afirmou, é necessário observar que delimitações dialetais não coincidem com limites, divisas e fronteiras territoriais administrativas. Por mais óbvio que isso possa parecer, o dialetólogo, ao definir uma rede de pontos para coleta de dados por meio de pesquisa de campo, não dá conta do emaranhado de questões sociais, históricas e culturais que caracteriza seja uma localidade isolada, seja uma microrregião. E, se essas questões se colocam previamente à seleção de uma rede de pontos, tornam-se também alvo de investigação posteriormente à coleta, à descrição e à análise dos dados, afinal, se a história interfere na configuração dialetológica do espaço, esta também, por sua vez, pode interferir na história ou, pelo menos, levar a questionamentos sobre o que se sabe da história de um dado lugar.

\section{Possíveis interpretações históricas da divisão espacial da língua em Minas Gerais}

Neste texto, interessam particularmente as propostas de dialetação para Minas Gerais feitas por Nascentes e por Zágari, sem que se pretenda, porém, discutir qual das duas é correta ou, pelo menos, é mais correta do que a outra. Acreditase que ambos os pesquisadores, em momentos diferentes, com enfoques e metodologias diferentes, têm, na verdade, o mesmo fundamento epistemológico e valem-se dos instrumentos cartográficos da mesma forma. Além disso, essas são as únicas propostas dialetais para o estado.

A pergunta que se propõe neste texto (à qual não se pretende responder de forma conclusiva, mas por meio de uma reflexão mais aprofundada do que a que em geral se encontra na bibliografia da área) é: que interpretações históricas seriam viáveis para as grandes áreas dialetais mineiras?

Zágari, depois de propor formalmente, em 1998, a tripartição dos dialetos mineiros, chegou a sugerir, em algumas comunicações orais, que os três falares se explicariam historicamente da seguinte maneira: o falar baiano teria se desenvolvido em Minas Gerais graças às atividades em torno do Rio São Francisco, as quais teriam garantido a convergência 
linguística de falantes do norte do estado e do sul da Bahia; o falar paulista, devido às Entradas e Bandeiras; o falar mineiro estaria ligado à mineração.

A proposta de Nascentes aponta a existência deum falar fluminense em Minas Gerais que poderia ser explicado pela atividade cafeeira na Zona da Mata mineira, que colocou essa região em contato direto com o Rio de Janeiro.

Essas explicações podem ser averiguadas, mas é necessário, antes de tudo, admitir-se que elas assentam-se sobre algumas crenças que, se não declaradas, são, pelo menos, pressupostas, como: (i) o estado divide-se em grandes regiões; (ii) para a existência de cada uma dessas grandes regiões, há uma explicação histórica genérica; (iii) língua e história são espelhares e podem ambas ser refletidas na superfície de um mapa.

Para tratar melhor essas e outras questões, as próximas seções serão dedicadas a expor como os historiadores costumam interpretar o espaço mineiro e como ele costuma ser representado segundo as diversas tendências cartográficas que vão do século XVIII até o presente. Para tanto, serão apresentadas e discutidas noções relativas a mapas situacionistas, mapas baseados em mosaico, micro-história, entre outras.

\section{A problemática do espaço em Minas Gerais}

\subsection{A visão naturalista e determinista do espaço mineiro}

Desde o século XIX, as explicações sobre a gênese territorial dos povos dependeram da articulação proposta entre a história e o espaço geográfico, ou, em sentido antropológico, entre cultura e natureza. Numa acepção tradicional, tratava-se de conceber a "região natural", definida por sua descrição física - relevo, clima, vegetação, hidrografia encerrada na "região geográfica", que se expressa por meio das ações humanas. Configuraram-se duas vertentes: as análises deterministas, submetendo a história das sociedades às forças da natureza, ou as explicações possibilistas, que apreendiam a transformação cultural do meio (como habitat). Apesar de este texto não poder dar conta da complexa discussão sobre a chamada Geografia tradicional (ou científica) que atualmente ocupa a pesquisa acadêmica, registra-se que, de qualquer modo, mantinha-se a clivagem significativa entre objeto da 
natureza e sujeito cultural, sendo aquele um referente básico do processo histórico. A delimitação regional sustentou-se numa geografia do espaço.

Esses moldes regionais ainda são utilizados para desenhar as pesquisas históricas relacionadas ao universo cultural e linguístico de Minas Gerais. Ele é, com efeito, demasiadamente vigoroso em termos de memória histórica. Já o botânico francês Saint-Hilaire, no início do século XIX, seguindo a racionalidade iluminista que juntava poder político, economia e região natural, observava a necessidade de obedecer à divisão naturalista das comarcas da província de Minas:

Desse modo, teríamos geralmente, na Comarca do Rio das Mortes [no sul] pastagens descobertas, e uma população agrícola e pastoril; na comarca de Vila Rica [sudeste], uma região florestal e aurífera; na do Serro do Frio [nordeste], florestas ainda e uma população menos composta de mineradores do que de homens dedicados à cultura das terras. A Comarca de Sabará [norte] ofereceria, geralmente, pastagens semeadas de árvores pouco desenvolvidas, uma população ocupada com o pastoreio, mas que não sabe ter com o gado cuidados tão racionalizados como os lavradores do Rio das Mortes. A Comarca de Paracatu [noroeste] [...] acha-se compreendida em limites perfeitamente naturais; constitui uma zona cuja população é bastante análoga àquela com que se limita pelo lado do oriente [...]. (SAINT-HILAIRE, 1975, p. 47).

As observações naturalistas viraram modelo entre os descritores da geografia mineira, ainda no século $\mathrm{XX}$. O território fora urdido por seu conjunto orográfico, fundado na cadeia Mantiqueira-Espinhaço, onde se situavam as minas de ouro. A cadeia montanhosa seria a espinha dorsal, no sentido sul-norte, da sua unidade geofísica, dividida, porém, por suas quatro bacias hidrográficas - rio Doce, rio São Francisco, rio Grande, rio Jequitinhonha -, constituindo as supostas regiões naturais ou paisagens das antigas comarcas da capitania de Minas Gerais (ibidem).

Com efeito, as distinções regionais ou naturais não impediram que se privilegiasse a unidade do meio geográfico (natural, econômico, social), a fim de se entender a "formação do espírito mineiro" (TORRES, 2011). A cultura de Minas seria a síntese resultante das camadas sociais e culturais distintas 
que, sobrepondo-se e integrando-se no curso da história, forjaram um modo de vida singular. Torres, em ensaio de viés determinista, nos anos 1940, chega a cunhar a expressão do fenômeno de uma história social submetida às injunções da geografia física: "cultura em conserva", duradoura. Em Minas Gerais, principalmente, haveria verdadeiras "ilhas culturais", "que ficam à margem das transformações pelas quais passa a história do país. São lugares onde podemos estudar a vida passada in vivo, sem documentos, mas olhando as pessoas que vivem aquela situação, em outras partes já superada" (TORRES, 2011, p. 58).

A identidade do mineiro, portanto, balizada pelo espaço unificado e pela história das origens comuns - baseada no tripé setecentista: mineração, imaginário barroco, política liberal ou libertária -, resistiu ao jogo dos ritmos temporais e à diversidade social dos lugares. Mesmo quando se previam as diferenças locais (da paróquia ou do município) e/ou regionais, uma personalidade mineira ou das Minas mantinha-se, como nas conhecidas palavras de Guimarães Rosa: "Minas é muitas" (itálico nosso).

Nas interpretações convencionais que articularam a dimensão geográfica à linhagem temporal, o espaço torna-se a realidade física, visível, que se quer delimitar ou distinguir por sua natureza. Trata-se assim de território que se domina com o olhar, determinado pela cartografia. $\mathrm{O}$ relevo surge como o "guardião" da fronteira naturalizada:

Ao atravessar indiferentemente os territórios, lá se destaca o relevo, já "divisor" de águas, delimitando universos. A natureza, assim, adquire o significado que os olhos pretendem lhe fornecer. O conjunto geomorfológico adquire o significado de limite, indiferente à sua própria topografia e ao sentido tomado pelas águas. As cartografias, contudo, fornecendo-lhes o significado de divisor. (HISSA, 2006, p. 31).

A visão de Torres, como se como se pode notar, é a mesma que se encontra nas concepções acríticas das pesquisas que se firmaram por longa data. Nela, mantém-se a delimitação estática (ou geofísica) do espaço, em detrimento das relações socioculturais dinâmicas que determinam qualquer experiência de lugar, o que não impediu que surgisse a noção de mosaico, bem mais reveladora do que as limitações do polígono. 
4.2 Visões situacionistas do espaço mineiro

Saindo da perspectiva naturalista, Cunha et al., partindo da perspectiva da história econômica propõem para a capitania de Minas Gerais no século XVIII a seguinte divisão: "Minas", "Curraleira", "sertão[oriental/leste]", "sertão [ocidental/oeste]", "Campos sul", conforme figura 7:

Figura 7 - Capitania das Minas Gerais, séc. XVIII

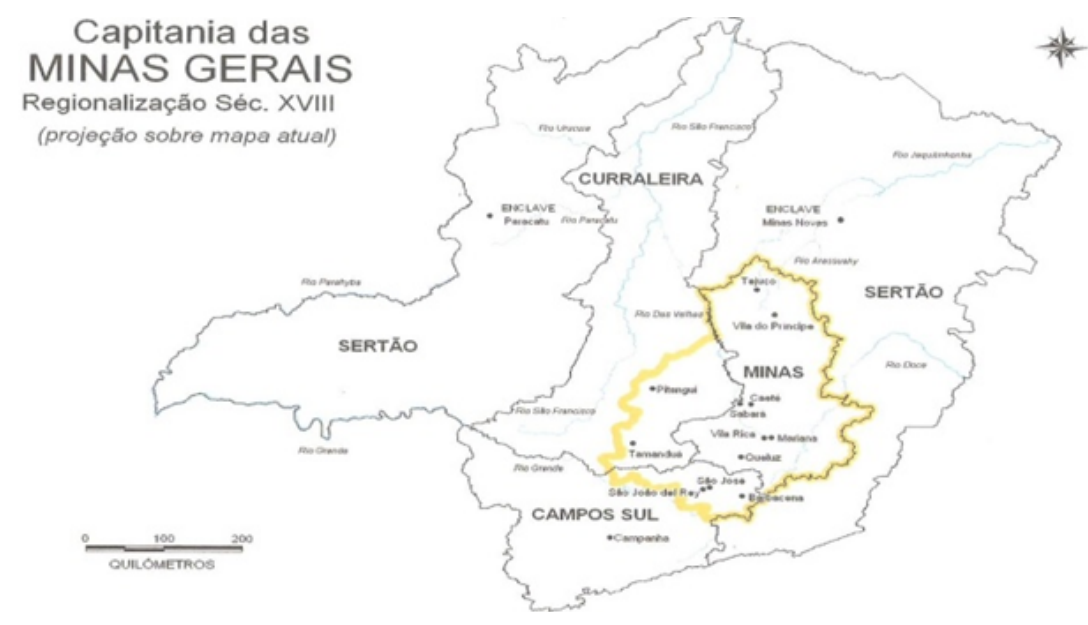

Fonte: Cunha et al. (2008)

Note-se que os autores usam como referência o contorno do atual mapa geopolítico de Minas Gerais e nele inserem as regiões que, de forma mais próxima no espaço físico, circundavam o centro econômico da capitania, a saber: a região que eles chamam de "Minas" e que economicamente caracteriza-se pela mineração, tendo seu centro em Vila Rica. Do ponto de vista econômico, somente na passagem do século XVIII para o XIX as demais regiões, além dessa central, começariam a se destacar.

Para o século XIX, Paiva e Godoy (2002) propõem vários mapas diferentes com a regionalização do estado, segundo critérios diversos. Os mapas 8 e 9 mostram as regiões mais desenvolvidas do estado segundo, respectivamente, o comércio interregional e interprovincial que ocorria no estado no século XIX conforme informações dos viajantes da época. As regiões constantes nessas duas figuras vêm, segundo os 
mesmos autores, de um mapa proposto no século XIX cuja origem se encontra explicada na figura 9. Esse mapa propõe para o estado as seguintes regiões: Extremo Noroeste, Vale do Alto-Médio Rio São Francisco, Sertão, Minas Novas, Triângulo, Araxá, Paracatu, Sertão do Alto Rio São Francisco, Sertão do Rio Doce, Diamantina, Vale do Médio-Baixo Rio das Velhas, Intermediária de Pitangui-Tamanduá, Mineradora Central Oeste, Mineradora Central Leste, Mata, Sudeste, Sul Central e Sudoeste. Tanto na figura 8 quanto na figura 9, vê-se que as regiões de baixo, médio e alto desenvolvimento coincidem e que cada uma delas em particular tem sua especificidade e serve de uma determinada maneira às rotas comerciais. $\mathrm{O}$ trabalho de Paiva e Godoy traz outros mapas de regionalização de Minas Gerais elaborados sob outros critérios que não só o comercial e todos têm, assim como os das figuras 8 e 9, divisões com regiões bem menores do que as grandes regiões de Nascentes e de Zágari.

Figura 8 - Regionalização de Minas Gerais, segundo Paiva e Ggodoy; mapa 13

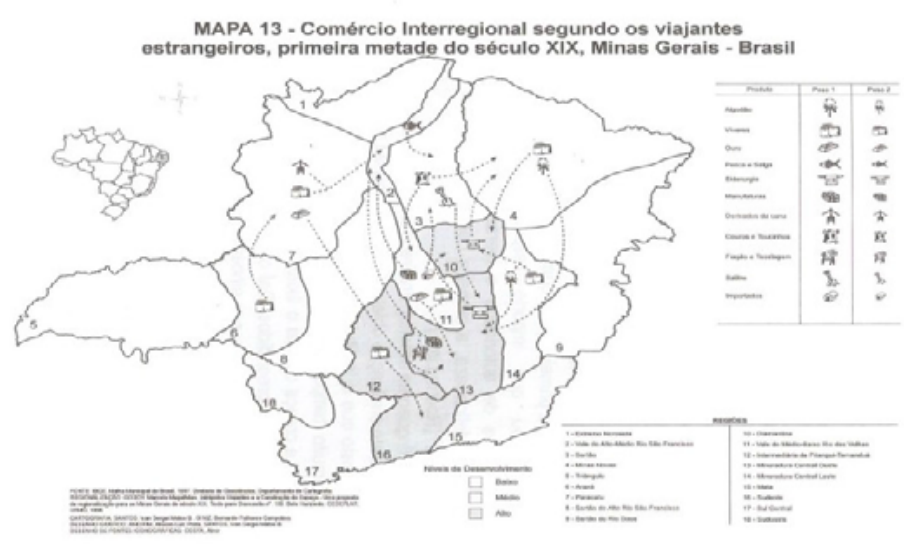

Fonte: Paiva; Godoy (s/d) 
Figura 9 - Regionalização de Minas Gerais, segundo Paiva e Ggodoy; mapa 13

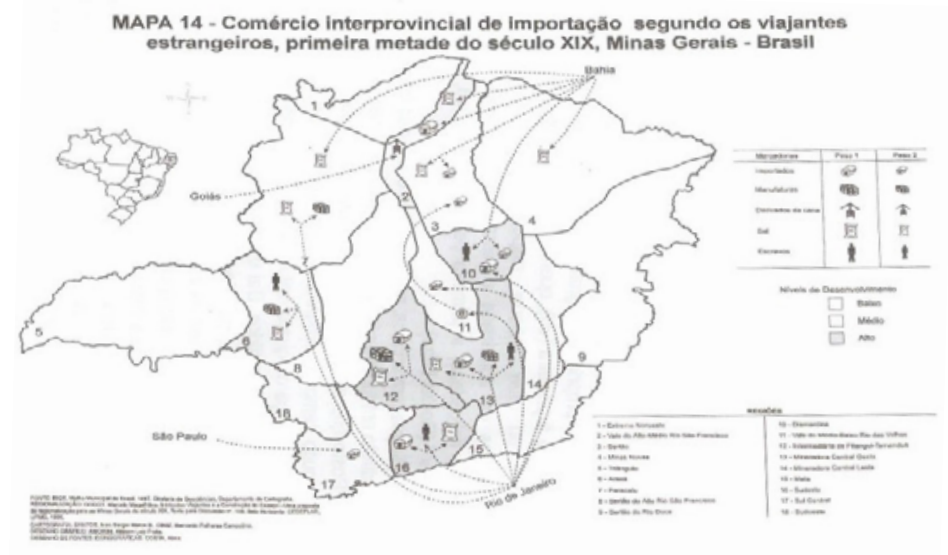

Fonte: Paiva; Godoy (s/d)

Paiva e Godoy trabalham com a noção de microrregiões e entendem que as relações entre elas se reconfiguram a cada critério que se adote. Por isso, pode-se chamar esse tipo de cartografia de situacionista. Já as divisões de Nascentes e de Zágari compartilham noções da cartografia tradicional, que defende a existência de grandes áreas regionais recortadas segundo vários critérios simultâneos.

As microrregiões expostas pela cartografia situacionista só podem ser explicadas à luz da microhistória e não comportam visões tradicionais que relacionem, na superfície do mapa, de forma aparentemente óbvia, grandes acontecimentos históricos com grandes áreas geográficas. A propósito, veja-se o que diz Massey sobre as cartografias situacionistas:

Cartografias situacionistas, na medida em que ainda tentam retratar o universo, mapeiam esse universo como não sendo uma ordem única. Por um lado, as cartografias situacionistas buscam desorientar, desfamiliarizar, provocar uma visão a partir de um ângulo inusitado. Por outro lado, [...] buscam expor as incoerências e fragmentações do próprio espaço [...]. (MASSEY, 2008, p. 160-162).

Adentrando-se, mesmo que parcialmente, na história da cartografia mineira, pode-se perceber que os atos de instituição do espaço - por meio da manipulação de mapas - muito contribuíram para distinguir (ou conceber), numa continuidade 
territorial, a região, supondo-se que esta significasse um documento da natureza a serviço dos planos ou das estratégias político-administrativas. Os mapas, nesse sentido, foram instrumentos da objetividade territorial do poder. Daí a face cartográfica assumir diferentes contornos ao longo do tempo, atestando os processos complexos da configuração territorial, especialmente entre os séculos XVIII e XIX, e ainda os equívocos de uma perspectiva teleológica do recorte regional. Quando se manuseiam os mapas geográficos como se estes produzissem a moldura mineira, arrisca-se prender-se a essa pretendida carga de objetividade. Inscrever um objeto no mapa, então, exige bastante cautela, para não se reproduzir a história do poder convertida à dimensão cartográfica.

\section{Como conciliar a cartografia crítica de Minas Gerais com os trabalhos dialetológicos?}

Conforme se viu, os estudos dialetológicos em Minas Gerais indicam a existência no estado de grandes áreas dialetais. Uma vez que a língua, bem como os usos culturais, não muda bruscamente, supõe-se que essas grandes áreas tenham origem no passado, ou melhor, nos movimentos migratórios que ocasionaram o povoamento do estado de acordo com as atividades diversas que em seu território se desenvolveram.

No entanto, os recentes estudos históricos não dão suporte para que se interpretem as grandes áreas a partir de grandes e decisivos acontecimentos. Nem mesmo os exemplos de mapas apresentados nas últimas seções, elaborados à luz de uma cartografia que assume melhor o caráter representativo do espaço no mapa - ao contrário da cartografia clássica, que acreditava no caráter supostamente exato do mapa como "fotografia" do espaço -, são capazes de mostrar todos os atributos regionalmente localizados que, de forma dinâmica, no fluxo ininterrupto do tempo, levam à espacialização de um dado fenômeno. Além da espacialização geográfica - de ordem mais física - e da econômica, seria necessário considerar, na compreensão do espaço a que se denomina Minas Gerais, uma série de outros elementos, tais como: o ritmo e a natureza do povoamento/migrações, a composição urbana, as instâncias educativas, a urdidura político-administrativa, as sociabilidades religiosa ou intelectual, transporte, educação, 
entre alguns outros também muito relevantes. Devem-se observar ainda as específicas confrontações étnicas em partes do território mineiro, que envolveriam as atuações de brancos nativos do Brasil ou europeus, africanos, crioulos, mestiços e diferentes povos indígenas.

Nesse sentido, a cartografia situacionista e a de mosaico, representadas nos mapas de Cunha et al. (2008) e de Paiva e Godoy (2002), são um grande avanço face à cartografia naturalista, mas ainda são insuficientes para que se absorvam, por meio da superfície do mapa, o maior conjunto possível de elementos necessários à interpretação de um dado fenômeno, como o linguístico. Tais elementos indicam que a experiência social plasmada num território é sempre singular - como urdidura -, conforme as indicações da denominada microhistória, embora ela possa estar na órbita de um centro hegemônico, que nela se inscreve. Portanto, as generalizações que não compreendem o jogo das variáveis, na realidade, reproduzem os estereótipos de uma síntese geo-histórica, uma síntese sempre ingênua e excessivamente simplificadora como a que seria necessária para explicar a existência de grandes áreas dialetais num dado território.

Os documentos cartográficos, performativos da dinâmica social e política, não são simplesmente descritores da realidade do espaço, mas seus construtores, reprogramadores. Os mapas cartográficos (topográficos, geodésicos) aplicados às pesquisas históricas, ademais, com seu grafismo visual, embora sejam valiosos à representação da simultaneidade dos fatos ou dos acontecimentos, não se prestam, como as narrativas, às leituras da variação dos ritmos e aos processos diacrônicos mais complexos, incluindo o traçado oscilante da duração.

Essas observações podem levar à conclusão de que o mapa é um instrumento falacioso para análise do espaço e da realidade que nele se encontra. Gomes $(2005$, p. 27) adverte: "é possível ler através do mapa desde que se conheça e se considere as condições de sua produção; os dados, a realidade que estaria além do mapa, podem ser explorados desde que nos limites claros do processo de representação que é o mapa e dos limites materiais e cognitivos da sua fabricação".

As grandes áreas dialetais do estado podem ser explicadas apenas à luz de uma cartografia crítica, atualizada, que se preste a uma análise histórica também crítica. 
Não se está aqui negando, de forma alguma, a diversidade dialetológica registrada nas cartas dos atlas e trabalhos afins; o que se faz, sim, é mostrar que essa realidade não pode ser interpretada de forma espelhar por mapas que tratem de outros fenômenos que não o estritamente linguístico, apesar do alto alcance que os próprios dialetólogos propõem à interdisciplinaridade inerente ao seu objeto de estudo, conforme se viu na introdução deste artigo.

Espera-se que essa reflexão possa contribuir com o refinamento do uso da cartografia nos estudos dialetológicos não só de Minas Gerais, mas nos estudos dialetológicos em geral.

\section{REFERÊNCIAS}

ANTUNES, L. B.; RANGEL, C. V. A. R. Descrição das vogais orais do português falado na região do Vale do Aço. Principium, v. 1, 2001, p. 93 - 103.

ARAGÃO, M. do S. S. de; MENEZES, C. P. B. de. Atlas linguístico da Paraíba. Brasília: CNPq/UFPB, 1984. 2v.

BARROS, D. S. C. Na fronteira entre Rio e Minas: caracterização das regiões dialetais e estudos sobre o /S/ em coda no continuum linguístico RJ-BH. In: III CONGRESSO INTERNACIONAL DE DIALETOLOGIA E SOCIOLINGUÍSTICA, 2014, Londrina. III CIDS - Congresso Internacional de Dialetologia e Sociolinguística: Caderno de Resumos, 2014. v. Único.

BRASIL. Decreto $n^{0}$ 30.643/1952. Disponível em: <http://www2. camara.leg.br/legin/fed/decret/1950-1959/decreto-30643-20-marco1952-339719-publicacaooriginal-1-pe.html >. Acesso em: 10 dez. 2014.

CARDOSO, S. A. Geolinguística: tradição e modernidade. São Paulo: Parábola, 2010.

COHEN, M. A. A. de M. A importância dos projetos 'Filologia Bandeirante' (1998-2002) e 'Pelas Trilhas de Minas: as bandeiras e a língua nas Gerais' (2002-2004) para descrição e análise da diversidade linguística de Minas Gerais. In: COHEN, M. A. A. de M. et al. (org.) Anais do $1^{\circ}$ Encontro sobre a Diversidade Linguística de Minas Gerais: cultura e memória. Belo Horizonte: Faculdade de Letras da UFMG, 2011. 222p. 
CUNHA, A. M. et al. Espaço, paisagem e população: dinâmicas espaciais e movimentos da população na leitura das vilas do ouro em Minas Gerais ao começo do século XIX. Revista Brasileira de História, São Paulo, v. 27, n. 53, 2007, p. 124.

CUNHA, A. M. et al. História Econômica e Regionalização: Contibuição a um Desafio Teórico-Metodológico. Est. Econômicos, São Paulo, v. 38, n. 3, p. 493-524; jul.-set. 2008.

FERREIRA, C. da S. et al. Atlas linguístico de Sergipe. Salvador, UFBa: Instituto de Letras/Fundação Estadual de Cultura de Sergipe, 1987.

GOMES, M. do C. A. de A. Mapas e mapeamentos: dimensões históricas; as políticas cartográficas em Minas Gerais (18501930). Belo Horizonte: FAFICH/UFMG, 2005. p. 27. (Tese em História).

HISSA, C. E. V. A mobilidade das fronteiras. Inserções da geografia na crise da modernidade. Belo Horizonte: Editora UFMG, 2006. p. 21.

MASSEY, D. Pelo espaço: uma nova política da espacialidade. Tradução Hilda Pareto Maciel e Rogério Haesbaert. Rio de Janeiro: Bertrand Brasil, 2008.

NASCENTES, A. Bases para a elaboração de atlas lingüístico do Brasil, vol. I. Rio de Janeiro: Casa de Ruy Barbosa, 1958.

. O linguajar carioca. 2. ed. Rio de Janeiro: Organização Simões, 1953.

AGUILERA, V. de A. Atlas linguístico do Paraná-ALPR. Curitiba: Imprensa Oficial do Estado, 1994.

OLIVEIRA, M. M.; COSTA, Milena Lepsch; Calegário, P. M. S. D.; CUNHA LACERDA, Patrícia Fabiane Amaral da. A história social da língua portuguesa em Juiz de Fora no século XIX. Principia, Juiz de Fora, v. 16, p. 136-143, 2013.

PAIVA, C. A.; GODOY, M. M. Território de contrastes: economia e sociedade nas Minas Gerais do século XIX. In: X Seminário sobre economia Mineira. Disponível em: <http://www.researchgate.net/ publication/4805244_Territrio_de_contrastes_-_economia_e_sociedade das_Minas_Gerais_do_sculo_XIX.> Acesso em: $10 \mathrm{dez} .14$.

Projeto Atlas Linguístico do Brasil. Disponível em: <www.alib. ufba.br>. Acesso em: 30 nov. 2011. 
RAMOS, J. M. Três falares de Minas: releitura sociolinguística de uma proposta dialetológica. In: II Congresso Internacional de Dialetologia e Sociolinguística: Diversidade Linguística e Políticas de Ensino, 2012, Belém (PA). Apresentação oral.

RIBEIRO, J. et al. Esboço de um Atlas Lingüístico de Minas Gerais - v. 1. 1. ed. Rio de Janeiro: Fundação Casa de Rui Barbosa; Juiz de Fora: Universidade Federal de Juiz de Fora, 1977.

RIBEIRO, P. R. O. (Re)descobrindo o falar mineiro através da história social da Zona da Mata. Início: 2013. Tese (Doutorado em Doutorado em Linguística) - Universidade Federal de Juiz de Fora.

RIBEIRO, P. R. O.; SOARES, M.S. ; CUNHA LACERDA, P. F. A. da. . A realização da noção de existência no mineirês : um estudo da variação dos verbos ter, haver e existir. Revista Signótica, v. 25, p. 533-559, 2013.

ROCHA, A. P. A. A importância do 'Esboço de um Atlas Linguístico de Minas Gerais' (1977) e do Projeto "Atlas Linguístico do Brasil" para a descrição e análise da diversidade linguística de Minas Gerais. In: COHEN, M. A. A. de M. et al. (org.) Anais do $1^{\circ}$ Encontro sobre a Diversidade Linguística de Minas Gerais: cultura e memória. Belo Horizonte: Faculdade de Letras da UFMG, 2011. 222p.

ROCHA, A. P. A.; ANTUNES, L. B. Divisão dialetal em Minas Gerais: notas sobre os aspectos fonéticos. In: Razky, A.; Lima, A. F. de; Oliveira, M. B. de; Costa, E. O. da. (Org.). Estudos Sociodialetais do Português Brasileiro. 1ed. Campinas: Pontes, 2014, v. 1, p. 97-111.

ROCHA, A. P. A.; RAMOS, J. M. Estudos de dialetologia em Minas Gerais: breve histórico. Estudos, Salvador, v. 41, p. 71-86, 2010.

ROSSI, N. Atlas prévio dos falares baianos. Rio de Janeiro: MEC/ INL, 1965.

SAINT-HILAIRE, A. de. Viagem pelas províncias do Rio de Janeiro e Minas Gerais. Tradução de Vivaldi Moreira. Belo Horizonte: Itatiaia; São Paulo: Edusp, 1975. p. 47.

SEABRA, M. C. T. C. ATEMIG - Atlas Toponímico do Estado de Minas Gerais: variante regional do Atlas Toponímico do Brasil. In: MAGALHÃES, J. S.; TRAVAGLIA, L. C. (org.). Múltiplas perspectivas em Linguística. Uberlândia: EDUFU, 2008. p. 1945-1952. 
STALEY, D. J. Sobre lo visual en Historia. Revista Digital de Historia Iberoamericana, v. 2, n. 1, 2009, p. 16. Disponível em: $<$ http://revistahistoria.universia.net>. Acesso em: 19 set. 2010.

TORRES, J. C. de O. O homem e a montanha. Introdução ao estudo das influências da situação geográfica para a formação do espírito mineiro. Belo Horizonte: Autêntica, 2011. p. 58.

ZÁGARI, M. R. L. Os Falares Mineiros: Esboço de um Atlas Lingüístico de Minas Gerais. In: AGUILERA, V. de A. (org.). A Geolingüística no Brasil: caminhos e perspectivas. Londrina: Ed. UEL, 1998, p. 31-54.

\section{Abstract \\ The relationship between Dialectology and History: Methodological and theoretical reflections for the study of the Portuguese spoken in Minas Gerais}

This text presents a summary of the dialectological projects that have been developed in Minas Gerais. The description of the variation of Portuguese used in this state suggests a delimitation of two or three basic dialectal areas - division which can apparently be explained through historical factors. This text aims to discuss the problems that might arise due to the attempt to explain the state dialectal division in the light of traditional History, disregarding factors such as the dynamism of time, space and social relations existing among the speakers of this language.

KEY-WORDS: Dialectology; History; Minas Gerais; Minas dialects 